\title{
Correction to: Detecting changes in copper technology by analyzing slag from Nahal Amram Israel
}

\author{
Sana Shilstein ${ }^{1}$ • Tal Kan-Cipor Meron ${ }^{2}$ - Sariel Shalev Sa, $^{2,4}$ \\ Published online: 2 August 2020 \\ (C) Springer-Verlag GmbH Germany, part of Springer Nature 2020
}

\section{Correction to: Archaeological and Anthropological Sciences (2020) 12: 96} https://doi.org/10.1007/s12520-020-01047-9

Author "Uzi Avner" asked to remove the name in the list of authors of the paper. The request was agreed by the co-authors. Given in this article is the corrected list.

Publisher's note Springer Nature remains neutral with regard to jurisdictional claims in published maps and institutional affiliations.

The online version of the original article can be found at https://doi.org/ $10.1007 / \mathrm{s} 12520-020-01047-9$

Sana Shilstein

sana.shilstein@weizmann.ac.il

Tal Kan-Cipor Meron

tkan-cipo@staff.haifa.ac.il

Sariel Shalev

sariel.shalev@univ.haifa.ac.il

1 Faculty of Physics, Weizmann Institute of Science, 76100 Rehovot, Israel

2 Charney School of Marine Sciences, University of Haifa, Mount Carmel, 31905 Haifa, Israel

3 Department of Archaeology, University of Haifa, Mount Carmel, 31905 Haifa, Israel

4 Weizmann Institute of Science, 76100 Rehovot, Israel 